\title{
Open access and connectedness: stimulating unexpected innovation through the use of institutional open archives
}

Johann van Reenen

University of New Mexico, USA

M Sc, 1975, University of Pretoria, África do Sul

E-mail: jreenen@unm.edu

\begin{abstract}
The author reviews past work with Ibict and the global progress made by the Open Access Movement. He postulates a theory of open access being an example of a complex adaptive system created by Internet-based scholarly publishing. Open access could be the cause of a cascade of increasing complexity and opportunities that will reshape this system. He has chosen the pervasive and global "Connectedness" created by the internet and the content spaces it provides for open access collections as a "simple disruptive agent". He discusses how connectedness influences infinite variety, creativity, work, change, knowledge, and the information economy. Case studies from the University of New Mexico Libraries are used where appropriate.
\end{abstract}

\section{Keywords}

Digital libraries. Open access. Open archives. Scholarly publishing. Institutional repositories. Complex adaptive systems. Connectedness. Complexity. Social software.

\section{Acesso aberto e conexidade: estimulando inovações inesperadas com o uso de arquivos abertos institucionais}

\section{Resumo \\ $O$ autor revisa um trabalho passado feito com o lbict e o progresso mundial do Movimento de Acesso Aberto. Ele apresenta e defende a teoria de que o acesso aberto é um sistema adaptativo complexo criado a partir da publicação acadêmica utilizando a Internet. $O$ acesso aberto poderia ser a causa de uma cascata de complexidade crescente que leva a oportunidades que modificarão o sistema. Ele escolheu a conexidade global que se espalha, criada pela Internet e pelos espaços de conteúdo que ela proporciona para coleções abertas, como um 'agente simples para quebras do status quo'. Ele discute a influência da conexidade nas infinitas variedades, na criatividade, no trabalho, na mudança, no conhecimento e na economia da informação. Estudos de caso das Bibliotecas da Universidade do Novo México são apresentados.}

\section{Palavras-chave}

Bibliotecas digitais. Acesso aberto. Publicações acadêmicas. Repositórios institucionais. Sistemas adaptativos complexos. Conexidade. Complexidade. Software social.

\section{INTRODUCTION}

"The Open Access (OA) movement again occupied center stage in the journals marketplace in 2005, eclipsing issues of price, publisher mergers, and big deals. Public policy measures involving open access were taken up in venues all over the globe. Debate was vigorous and contentious in the United States and Britain, where sweeping initiatives were proposed." Van Orsdel \& Born, Library Journal, April 15, 2006.

The author has had the great honor to work with the Instituto Brasileiro de Informação em Ciência e Tecnologia (Ibict), especially Dr. Helio Kuromoto and his staff, since 2003. He was fortunate to arrange a visit to Ibict on 9 December 2003 to propose that the Brazilian government and/or Ibict make a statement in support of the global open access movement (specifically the Berlin Open Access Accord) during the 50th Anniversary year of Ibict. We decided that the Second Annual ISTEC/ Fapesp (Ibero-American Science $\mathcal{E}$ Technology Education Consortium and Fundação de Amparo à Pesquisa do Estado de São Paulo) Digital Libraries Workshop at Unicamp in May 2005 would be an ideal opportunity to do so. The proposal was presented to ISTEC (1); was approved by their Board, and two statements were made (2) at the symposium, one from Ibict and one from the participating librarians. Since then much has happened in the electronic environment that has made open access a viable system of scholarly communications. Low-barrier implementations such as Institutional Repositories have proliferated and became fertile ground for innovation and experimentation. This article will explore examples of this and, most importantly, the effect of the connectedness created by open access and the webenvironment in general as a complex adaptive system. The Open Access Movement exhibits two of the characteristics of a complex adaptive system; the capacity of self-organization and emergent complexity, as we will see later.

Self-organization arises from intelligence in the remote clusters (or"nodes") within a network. This is potentially limitless in the OA environment as every continent 
and people in far flung cities now have initiatives of this type. Pascale (3) says that emergent complexity is generated by the propensity of simple structures (e.g. Institutional Repositories) to generate novel patterns, infinite variety, and often, a sum that is greater than the parts. For background in CAS theory the seminal works of Gell-Mann (4), Kauffman (5), and Holland (6) will be useful.

First however, we begin by reviewing current open access advances and issues.

\section{OPEN ACCESS TODAY}

To understand how open access has progressed we need to answer some legitimate questions raised by researchers and librarians:

What is the rationale for open access?; Is there a viable financial model for open access publishing?; Is the Open Access Movement global and credible?; How does it work at the institutional level? Is it difficult to do?

\section{What is the rationale for open access?}

Researchers publish their work to be read. The more that work is read and utilized in other research or find practical applications, the more it benefits their careers. Open access has proved to be a powerful agent in increased citation and utilization rates.

There is now a website (7) that tracks articles that document citation rates. On this site there is the following statement:

"Why might open access be of benefit to authors? One universally important factor for all authors is impact, typically measured by the number of times a paper is cited (some older studies have estimated monetary returns to authors from article publication via the role citations play in determining salaries). Recent studies have begun to show that open access increases impact."

One of the most recent articles posted there (8), confirms this with its findings that:

"Open-access papers were twice as likely as the password-protected articles to be cited four to 10 months after publication, and almost three times as likely from 10 to 16 months afterward."
Another important aspect of open access systems such as Institutional Repositories is the ability to archive all the intellectual and administrative publications of organizations such as Universities. Currently much of this work resides on departmental servers, personal computers, or in paper files and may be lost as researchers leave the organization. The inclusion of non-peer reviewed and administrative documents in institutional repository collections are controversial. To understand some of the issues better I suggest reading the diverse views debated by a panel of industry experts about what the future holds for open access arranged by the Research Information site of Oxford Journals Online ${ }^{\mathrm{TM}}$ (see: "Consensus is difficult in open-access debate" at http:// w w w.researchinformation.infol rijunjul06openaccess.html). Some proponents of open access supports the purist view that only peer reviewed and post-published articles constitute a true open access Institutional Repository. These schools of thought will probably continue to discuss the merits of a purist or allinclusive system for a while. In the meantime, many extremely useful collections are becoming available in Institutional Repositories such as biological and geological field notes, grant application preparations, graduate student research, and other material that were previously unavailable for study.

\section{Is there a viable financial model for OA publishing?}

If open access is successful in advancing the most important aim of research, dissemination, is it also part of the solution to the crisis in scholarly publishing? I believe it is one of a complex set of services that will moderate the financial issues confounding library budgets today. To make open access successful we need workable financial models.

The Open Access Movement in the United Kingdom has created a commendable suite of services dealing with financial models. Through JISC, the Joint Information Systems Committee (www.jisc.ac.uk/), they published an important report describing the technical, organizational and business models that could "underpin user-facing services to be developed over UK repositories". It is important that all open access proponents and practitioners read this. The complete report is available from the JISC digital repositories page: http://www.jisc.ac.uk/index.cfm? name= programme_digital_repositories 
Open access and connectedness: stimulating unexpected innovation through the use of institutional open archives

It is also important to encourage discussion and idea sharing among practitioners. It could be an important factor in the growth of the already successful Brazilian Open Access Movement. The email discussion lists used by JISC members are excellent examples (see: jiscrepositories for general cross domain issues, and cetismetadata for e-learning repositories and metadata issues). They also use a program wiki (http:// www.ukoln.ac.uk/repositories/digirep) to share information about the programs and projects as they grow. In fact, the JISC Information Environment is an example worth investigating by Ibict. It is envisaged as "a virtual place where members of colleges and universities can deposit and share useful content (e.g. research outputs). The current collection of JISC funded content has the potential to grow to embrace both externally generated content from publishers and aggregators and resources generated by the research communities. To achieve the latter, staff and students will need a 'place' or 'places' in which to lodge suitable content and products and a means for exchanging and adding to it." The FAIR (Focus on Access to Institutional Resources Program at: http:// www.jisc.ac.uk/index.cfm?name = programme fair) has been developed to create the mechanisms and supporting services for open access spaces, policies and the sharing of best practices.

\section{IS THE OPEN ACCESS MOVEMENT GLOBAL AND CREDIBLE?}

There are now many significant global Open Access Movements, the most important being:

- Budapest Open Access Initiative (December 2001) and the Berlin Declaration on Open Access to Knowledge in the Sciences and Humanities October 2003 see: http:// www.zim.mpg.de/openaccess-berlin/

- National Institutes of Health Rule of 2005 "requested" that its grantees put copies of their published articles in the agency's own online repository, PubMed Central (http://www.pubmedcentral.nih.gov/). This may be strengthened this summer as the U.S. House Appropriations Committee added a provision directing the NIH to "require" its research grantees to submit an electronic version of their final, peer-reviewed manuscript to PubMed Central upon acceptance for publication in a journal.

- US Federal Research Public Access Act of 2006 (FRPAA) will mandate the Open Access Self-Archiving of published journal articles; the author's final, corrected, refereed article. See: http://cornyn.senate.gov/ doc_archive/05-02-2006_COE06461_xml.pdf

- An April 2006 European Commission Report (executive arm of the European Union) recommends open access to all publicly financed research. See: http://ec.europa.eu/ research/science-society/pdf/scientific-publicationstudy_en.pdf

- The Research Councils UK (RCUK) issued on June 28, 2006, its open-access policy. They will require open access archiving from funded research: "Ideas and knowledge derived from publicly-funded research must be made available and accessible for public use, interrogation and scrutiny, as widely, rapidly and effectively as practicable."

In the June 2006 issue of the SPARC Open Access Newsletter (http://www.earlham.edu/ peters/fos/ newsletter/06-02-06.htm) there is a brief overview of more national movements on the brink of taking significant legal and/or policy steps towards open access posting compliance:

- There is an Open Access bill before the German Parliament

- Open Access policies have been adopted or are under consideration at the National level in Australia, Finland, Sweden, and South Africa

- India's National Institute of Technology has approved an OA mandate

To this we can now add the efforts of Ibict in Brazil and their symposium of August 2006!

In the United States citizens (thus taxpayers!) also seem to support open access. A May 2006 Harris Interactive ${ }^{\circledR}$ Poll showed the public's strong support (82\%) for open access to federally funded research results. See: "Americans support free access to research" at: http:// online.wsj.com/article email/SB114893698047965609. MyQjAxMDE2NDM4̄MTkzMzE2Wj.html

Recently Library Journal (April 15, 2006-"Journals in the time of Google") reported that as of "mid-February, the Directory of Open Access Journals (DOAJ) contained 2,044 peer-reviewed $O A$ journal. That is about 600 more than in 2005. 
Because of the above movements and initiatives I believe we can safely say that: Yes, the Open Access Movement is global and credible!

\section{How does it work at the institutional level? Is it difficult to do?}

Institutional Repositories are the most common implementations of local open access systems. Wikipedea defines institutional repositories (http://en.wikipedia. org/wiki/Institutional_repositories) as: "... an onlinelocus for collecting and preserving - in digital form - the intellectual output of an institution, particularly a research institution. For a university, this would include materials such as research journal articles (before (preprints) and after (postprints) undergoing peer review, and digital versions of theses and dissertations, but it might also include other digital assets generated by normal academic life, such as administrative documents, course notes, or learning objects. The two main objectives for having an institutional repository are:

- to provide open access to institutional research output by self-archiving it;

- to store and preserve other institutional digital assets, including unpublished or otherwise easily lost ("grey") literature (e.g., theses or technical reports)."

There are many options for open-source soft-ware and commercial systems to run an institutional repository. Some of the commonest free options in use are Dspace (http://www.dspace.org/), E-prints (http://www.eprints. org/), and a product developed at Unicamp called Nou Rau (http://libdigi.unicamp.br). All of these are OAI/ PMH compliant (Open Archives Initiative/Protocol for Metadata Harvesting). They are fairly easy to implement and maintain, and the processes for submission are easy to use. There are also systems of higher sophistication that can manage the complex relationships presented by digital objects but these also need more human and capital resources to implement and maintain. One of the leading free ware contenders at this level is Fedora ${ }^{\mathrm{TM}}$ from Cornell (http://fedora.redhat.com/). It is

"... An Architecture for Complex Objects and their Relationships. The Fedora architecture is an extensible framework for the storage, management, and dissemination of complex objects and the relationships among them. Fedora accommodates the aggregation of local and distributed content into digital objects and the association of services with objects. This allows an object to have several accessible representations, some of them dynamically produced. The architecture includes a generic RDFbased relation-ship model that represents relationships among objects and their components. Queries against these relationships are supported by an RDF triple store. The architecture is implemented as a web service, with all aspects of the complex object architecture and related management functions exposed through REST and SOAP interfaces. The implementation is available as open-source soft-ware, providing the foundation for a variety of end-user applications for digital libraries, archives, institutional repositories, and learning object systems."

Below are some of the types of items that have been submitted to my organization's institutional repository. Most of these were creative decisions made by the users (or submitters) because we have few restrictions on what can be posted by each Community in its Collections once they have been made aware of the purpose and consequences of posting. We believe that this is an area where too much rule-making will deter participation and limit creativity!

Examples of Items in the UNM Institutional Repository:

- Meetings and proceeding. For instance we host the minutes of the University's Board of Regents which they are required to make public

- Whitepapers, opinion pieces, grant preparation work. The latter is important as these ideas have merit and can stimulate other work even if a grant is not funded. It may also lead to new partners for resubmission of such a grant

- Local journal or other publication series. For instance, a professor in the Department of Economics at UNM, with the help of his graduate students, started a portal for the Nepal Studies Center (see: http:// nepalstudycenter.unm.edu/index.htm) for which they created a very easy and affordable journal publishing system based on our Dspace ${ }^{\mathrm{TM}}$ implementation. They created the website interfaces for the journals from the above website and then created the DSpace community and collections (see: https://repository.unm.edu/handle/ 1928/343) for the NSC. They currently have two startup journals: 
Open access and connectedness: stimulating unexpected innovation through the use of institutional open archives

- Himalayan Journal of Development and Democracy (see: http://nepalstudycenter.unm.edu/journals/ hjdd.htm)

- Liberal Democracy Nepal Bulletin (see: http:// nepalstudycenter.unm.edu/journals/LDNB/ldnb.htm)

- Association documents. We are in negotiations to become the official institutional repository for the American Indian Planning Association who has unique planning documents relating to developments in Tribal areas.

- Technical Reports

- Research data. For instance we have a large collection of Scanning Electron Microscope (SEM) images of cave microbiology (more about this below) collected from Karst systems (http://en.wikipedia.org/wiki/Karst)

Universities all over the world are experimenting with unique and interesting collections. At the University of Tennessee Libraries', for instance, they are creating an institutional repository collection of interactive 360 degree images of art objects, the Arrowmont Digitization Project (http://www.lib.utk.edu/arrowmont/grant.html) based on a commercial repository system, Digitool $^{\text {TM }}$ from ExLibris $^{\mathrm{TM}}$. This is a good site to get insights for building a high-end digital repository of unique artifacts presented dynamically.

To realize the true value of an Institutional Open Archive, however, universities will have to ensure that most of the scientific and scholarly publications (especially peer reviewed items) of their professors and researchers are posted in the university's institutional repository or in a subject institutional repository such as the portal we have created at UNM for Ornithology; the Searchable Ornithological Research Archive (SORA, see: http:// elibrary.unm.edu/sora/). SORA currently hosts ten of the most important ornithology journals from their inception. The full text is freely available. This was a joint project with a professor in Biology and the associations he works with. Two ways that we hope to encourage more participation in our institutional repository are:

- A project using graduate students to digitize and post UNM scholarly and creative works listed in the annual biographical supplements sent in by professors for promotion and tenure
- We are working with the Provost to create policies and incentives to encourage ongoing submissions of new works

Other current initiatives at UNM to encourage the use and support of new modes of scholarly publishing and electronic archiving based on open access principles include:

\section{- Scholarly communications advocacy}

- We hold an annual Symposium to build faculty awareness $(1997,2002+)$

- A decade of awareness building in the science \& engineering departments

\section{- Open Access Institutional Archive}

-Dspace@UNM

\section{- Subject Journal Archive}

- Searchable Ornithological Research Archive (SORA) (more about this later)

\section{- Digital Historical Archives}

- Online Archive of New Mexico (OANM)

- Western Waters

- Rocky Mountain Archive

- Grants to demonstrate and experiment with new ways of publishing, exposing important collections not currently easily available, and connecting scientists in new ways: the Latin American Knowledge Harvester and the Karst Information Portal. More about these later.

\section{- Information for authors who want to participate in} solutions to the scholarly publishing crisis:

- "Assign only non-exclusive copyright to publishers

- Submit articles posted on your website to the institutional repository - it is archived and made available to global searchers via metadata standards

- Edit and review for open access or more reasonable publishers

- Educate editorial boards of your primary journals 
- Investigate opportunities to publish affordable competitive alternatives to your primary journals

- Recruit a subject-based journal archive to your campus library. Such as the Searchable Ornithological Research Archive."

This is just a quick overview of some basic initiatives universities could do to participate in the Open Access Movement. There is a large body of literature providing more details. One of the best places to mine for any topic regarding open access is the SPARC Open Access Newsletter and the Free Online Scholarship (FOS) Newsletter Archive at http://www.earlham.edu/ peters/ fos/newsletter/archive.htm. Another important source of information, an edited book by Jacobs (Jacobs, N., Ed. Open Access: Key Strategic, Technical and Economic Aspects. Chandos, 2006) will be published in late July 2006. Pre-publishing information indicates that it will cover the rationale, history, economics, technology and culture of open access. It will provide views from major stakeholders, updates from around the world, and visions of the future.

Some of the above initiatives will be discussed in greater detail in the section on "Connectedness and infinite variety" below.

\section{OPEN ACCESS AS A NATURAL SYSTEM}

Emergent complexity is driven by a few simple patterns that combine to generate infinite variety. Kao (9) shows how one simple creative breakthrough can "evoke a cascade of increasing complexity. 'Simple' inventions such as the wheel, printing press, or transistor lead to 'complex' offshoots such as automobiles, cellular phones, electronic publishing, and computing."

My premise is that just so Open Access can be the cause of a cascade of increasing complexity and opportunities for scholarly communications. As alluded to in the introduction, open access can be equated with a "Living System", that is, it cannot be directed only disturbed by the unexpected emergence of new agents working on the system. An example is the rise of social tagging systems that supports self-selected communities of interest. One relatively small and isolated variation can produce huge effects while large changes may have little effect (3). This phenomenon is common in the information industry as will be seen later.
Although the technology and the history of the development of the internet is not simple, the subsequent pervasive and global "Connectedness" that arose spontaneously was a "simple creative breakthrough" arriving with unexpected impact and speed. No large management team, complex strategic plan, and huge financial project "created" the many levels of connectedness that exploded on the Internet in recent years. It happened through many small and unpredictable connections made by individuals, organizations, and small businesses who wanted to share their ideas and products. Connectedness as a creative breakthrough provides content spaces for open access systems such as institutional repositories. These in turn are beginning to act as simple disruptive agents in the traditional scholarly communication system. As Wilson and Hayward (10), not verbatim, says:

The increase in the degree of [electronic] connectedness constitutes the greatest change in life today. For it is not just that there is more change than ever before, but the inter-connectedness has changed the nature of change itself, making it more unplannable and unpredictable, more abrupt and dynamic than it has ever been or than our traditional organizational systems can handle.

We distinguish between Connectivity which is a physical link between systems, and "Connectedness" which is the personal, academic, partnership, and community connections people make based on seamless connectivity provided by today's electronic systems. It has changed everything we used to know about such partnerships, joint ventures and group work.

To illustrate what I have in mind let's look at an example of what "connectedness" as a disruptive agent has done to newspaper publishing. The social networks erupting on the internet such as MySpace ${ }^{\mathrm{TM}}$, Facebook ${ }^{\mathrm{TM}}$, Flickr ${ }^{\mathrm{TM}}$, and the huge community of Bloggers are based on the collective intelligence of communities of interest. These movements and services are disrupting traditional journalism, often being the first to report breaking news. The immediate opinions and comments from members that follow their "news" reports have made these services "experiential" rather than just passive news reading. This is a competitive advantage over television and printed news.

Let's look, for instance, at a person who asks: What does this city look like, how do I get there, what can I do there, what will it cost? These and many more questions 
Open access and connectedness: stimulating unexpected innovation through the use of institutional open archives

can be answered by combining or doing a "mashup" of two or more free services currently provided on the web. One can first go to a community-built reference source such as Wikipedia and then go to a photo sharing service such as Flick, then do a search on a travel site and visit a blog about the area. What's more, the information is current and based on real experiences of the social network of members constructing them. The person gets the "live" aspects and the community evaluations that they provide free! Steward Butterfield, co-founder of Flickr (a photo-sharing and community-tagging site), says it's the "eyes of the world" as quoted in Levy and Stone (11), who goes on to say:

"When news happens anywhere in the world, it's common for the first photographs not to be sent via news wire, but posted to a Flickr site." This was true for instance when three people posted photos of the destruction of the September 2004 bombing of the Australian Embassy in Jakarta before news persons could get there.

Market forces are strongly supporting such services and not necessarily their local library or newspaper! Bradley Horowitz says of his recent purchase of Flickr ${ }^{\mathrm{TM}}$ for Yahoo ${ }^{\mathrm{TM}}$ : "With less than 10 people [Flickr] had millions of users organizing that content for them [using social tagging], tens of thousands of users distributing that across the Internet, and thousands of people not on the payroll actually building the thing" (11) - an excellent example of what could result from one creative breakthrough based on connectedness.

\section{Connectedness and infinite variety:}

Connectedness is the driver behind open access without this change the open collections would still only serve local users. Open access in turn drives a great variety of possible implementations. As mentioned above, the Nepal Study Center's use of our local Dspace ${ }^{\mathrm{TM}}$ instance is a creative solution for a widely distributed community of political scientists who have very few means to get together in person but who has a demonstrated need for real-time and freely shared information. The website and DSpace-based journals cost less than 5000 US $\$$ to create, excluding the human effort it took. Below are two more examples of how we are capitalizing on our Dspace implementation.

a. Karst Information Portal (KIP at http://www.lib. usf.edu/KIP/) to promote innovation in solving global karst geology problems. Much of the world's future water supply will be drawn from karst-based geological systems and the caves typical of these areas. Despite the emerging critical nature of world karst terrains, the literature of caves and karst remains largely inaccessible and distributed in many languages. In collaboration with the Alliance for Innovation in Science $\mathbb{E}$ Technology Information (AISTI.org), the University of New Mexico, the US National Cave and Karst Research Institute, Los Alamos National Laboratory, and the University of South Florida we are developing the Karst Information Portal (KIP) to promote open access to karst, cave, and aquifer information and linkages among karst scientists. KIP responds to disciplinary needs by integrating individual scientists into a global network through the portal and its open access repository based on Dspace ${ }^{\mathrm{TM}}$ technology. Projects of this scope face unique challenges, but provide the opportunity for librarians and information scientists to develop unique means to promote linkages among scientists and promote knowledge discovery.

We currently have two small grants from AISTI. One was used to submit about 2000 Scanning Electron Microscope images of cave microbiology and their related metadata to the UNM DSpace instance. The other will be exploring DSpace plug-ins that will allow the scientists to download these images and add additional metadata and discussions using social software.

b. We have a grant from the US Department of Education, Technological Innovation for Foreign Information Access program (TICFIA) over four years that started in October 2005. A digital information project entitled, "University of New Mexico Harvester for Building Knowledge Streams in the Americas" will be coordinated by the Latin American and Iberian Institute (LAII) at UNM. We will be using Dspace and the Dspace harvester as part of a portal to address the challenge of identifying and maintaining stable and reliable Internet access to library and institutional collections and digitized archives about Latin America. The Latin America Knowledge Harvester (LAKH) will identify and index multidisciplinary Latin American content collections available throughout the Americas. LAKH will offer researchers a searchable interface pointing to institutional repositories that permit access to their collection contents based on the Open Archives Initiative/Protocol for Metadata Harvesting. The goal is to stimulate new Latin America scholarship through $\mathrm{LAKH}$ and the interaction of cross-disciplinary knowledge communities. Once again we hope to utilize emerging social software to accomplish the latter. 
As can be seen from the above, there are many emerging options for making open access collections useful in ways that will exceed the effectiveness of traditional uses of information. Connectedness is leading to infinite and unpredictable variety - which is also the basis of evolution!

\section{CONNECTEDNESS AND COOPERATION}

Connectedness and easy access to open information will change work behaviors and cooperation between workers and organizations. We are already seeing a welcome new phenomenon emerging in attitudes; the altruistic behaviors required from users of social software as described in sections above. This altruistic behavior also underlies the Open Access Movement. Together these two phenomena will expand options for cooperation by providing both the mechanisms and the content.

Wikipedia (http://en.wikipedia.org/wiki/Social software) describes Social software as enabling “... people to rendezvous, connect or collaborate through computermediated communication and to form online communities."

Early examples of this, Wiki's and Blogs, are now well established systems to allow the growth of understanding (Wiki), the growth of social groups based on an issue or ideas (Blogs). More and more Wiki's are used to document a project -we have one at UNM for our Dspace implementation to ensure that we learn together as each one of us finds new information or learn a new skill.

The two grants mentioned above will require members of the communities we are establishing to use social tagging to add value to repositories. Social tagging is a popular way to locate, classify, rank, and share Internet resources through the practice of tagging and inferences drawn from grouping and analysis of tags. "[Users] categorize their resources by the use of informally assigned, user-defined keywords or tags ... Most social bookmarking services allow users to search for bookmarks which are associated with given "tags", and rank the resources by the number of users which have bookmarked them. Many social bookmarking services also have implemented algorithms to draw inferences from the tag keywords that are assigned to resources by examining the clustering of particular keywords, and the relation of keywords to one another." (Wikipedia entry at http://en.wikipedia.org/wiki/Social_bookmarking).

This type of cooperation in real time between researchers based on content in an open access repository was not possible before the advent of social software and we have only seen the tip of the iceberg so far!

\section{CONNECTEDNESS AND WORK}

Much has been written about the developing internationally distributed virtual workforce. One result of this is the out-sourcing of electronic work. Large multinational companies now are organized to deliver 24 hour/ seven-days-a-week services with workers scattered around the globe. However, this way of working has not yet taken root to the same extend in the academic and research community. Open access content will enhance distributed virtual work especially when scientists in developing nations have access to the same information as other scientists. I authored a speculative piece (12) about how work and workers may behave in a future where most of their work and interactions will be virtual and disconnected from their physical location. One can speculate that in future digital workers will live in two realities; the@-Home-culture and the@-Large-culture. Knowledge workers of the future will be able to create a healthy balance between these two realities by working digitally in a global system and benefiting financially, but also living and participating fully in their local or national culture. Thus nationalism could co-exist with "globalism". The latter refers to participating in a global digital culture without reference to one's local culture, nationality, color or creed; in fact, being unshackled from local economic, cultural and religious bonds when functioning in the global digital workplace.

Ultimately this may lead to more tolerance and opportunities to distribute work and wealth in ways that equalize rather than divide people. The best current example is the enormous impact virtually outsourced work has had on the economy of India and the improvement in lifestyles of such workers.

\section{CONNECTEDNESS AND CHANGE}

As mentioned before in the discussion of how natural systems work, the increase in the degree of connectedness constitutes the greatest change in life today. The past cannot inform us any more about the future - it is coming at us with too much speed and force due to connectedness. What this means for the Open Access Movement is that we need to meet the expectations of users for speed, flexibility, and availability by encouraging Services Providers to incorporate new ways of working and cooperation into services overlaying repositories. 
Open access and connectedness: stimulating unexpected innovation through the use of institutional open archives

\section{CONNECTEDNESS AND THE INFORMATION ECONOMY}

As we have seen, one relatively small and isolated variation in a living system can produce huge effects while large changes may have little effect. This phenomenon is common in the information technology industry. Massive efforts to promote a superior operating system may not succeed, whereas a series of unexpected events may establish an inferior operating system, for instance MSDOS, as the industry standard (3).

The Internet and its global marketplaces represent a type of self-organizing system. No one is really in charge of the Internet or planned its "emergence". No particular country or organization is in charge of global markets, yet considerable coherence emerges from millions of independent, but connected, decisions. Malone \& Laubacher (13) point out that managing "such a massive and unpredictable explosion of capacity and creativity would have been beyond the skills of even the most astute and capable executives". The Internet could only have arrived by way of self-management and they believe "The Internet is the greatest model of a network organization that has yet emerged".

The Linux version of the UNIX operating system is another elegant illustration of a distributed complex adaptive system. The operating system was developed as free-ware that soon attracted the attention of more and more programmers. Software developers with altruistic attitudes contributed their own ideas and improvements. The Linux community grew steadily, soon encompassing thousands of people around the world, all sharing their work freely with one another. Soon, this loose, informal group, working without managers and connected mainly through the Internet, had turned Linux into one of the best versions of UNIX ever created (13).

Google ${ }^{\mathrm{TM}}$ is having the same effect on Libraries. In a recent Library Journal (14) article the authors ask: "Who would have guessed that in June 2005 Google would account for over $56 \%$ of referrals to research articles in HighWire journals, while PubMed Central, a renowned life sciences repository, would account for less than $9 \%$ ?" and " $72 \%$ of scholars surveyed for a report on selfarchiving confessed to using Google to find scholarly literature on the web." Thus many of our expensive bibliographic databases are by-passed for the convenience (but not accuracy!) of Google ${ }^{\mathrm{TM}}$, Yahoo ${ }^{\mathrm{TM}}$, and other web search services. The Library Journal article (14) is also important to read for their analysis of the current state of open access awareness and how it is impacting commercial journal publishing.

\section{CONNECTEDNESS AND MINING FOR NEW KNOWLEDGE}

"All aspects of work and business - all products, all activities, all methods - have an information structure at their core that has long been hidden, just like the genetic codes of plants." (Maruca, 1999)

Many organizations are beginning to realize the value of the information contained in their internal processes, such as information gathered for writing grants and information gathered during regular administrative activities. One of the most daunting challenges for Universities is maximizing the use of large data sets sitting around their campuses long after funded research projects are completed. These sets of raw data could be the source of much future discovery if warehoused and curated correctly, and the descriptions of such data are made openly available through an institutional repository. At my university the Library, the Vive President for Research and Economic Development, and the High Performance Computing Center are working together on ways of dealing with this issue. The University Libraries are proposing that such data sets be described in ways that will expose them - through connectedness - to different researchers that may have innovative ideas for re-using the data. The entries in the institutional repository would then point to the large data sets that can be hosted by the High Performance Computing Center.

Open access collections also add to the matrix for future data mining in general.

\section{CONNECTEDNESS, CREATIVITY AND COMPLEXITY}

How can libraries manage such a massive and unpredictable explosion of connectivity, capacity and creativity? Mainly by keeping up with trends in user behavior based on ubiquitous connectedness. It will become critically important to provide services within the customers' preferred electronic spaces, whether it is a hand held device, a virtual work space, or a regular laptop.

The advent of social software creates enormous capacity for innovation across large and free collections developed by the Open Access Movement. A recent 


\section{Johann van Reenen}

study of the potential of social software in education (16) states:

"Adoption of blogs, wikis, tagging, bookmarking services, folksonomies, social networking software, and media-oriented services (e.g., podcasting) has been extraordinary over the past few years. Information technology strategists must assess this "social software" to understand its applicability within higher education."

Their extensive review of the field is important to inform how the open access community can incorporate such service provision across open access databases and may, in turn, influence these developments.

\section{CONCLUSION}

The Internet is already a hive of creativity but with the advent of the "Living Web" (also called Web 2.0) we are seeing an explosion of web services based on collective intelligence and connectedness. The sharing of metadata in standardized ways has made the Internet even more conducive for cooperation and creativity.

We cannot allow all this connectedness to be based on non-academic information which is currently most of what is available on the internet. We must add as much open access academic content to this mix as fast as we can. The Open Access Movement has great promise to do this but governments and academic institutions will need to ensure participation through incentives, requirements, and policies.

\section{REFERENCES}

1. VAN REENEN, J. Could brazilian research organizations support the Berlin open access accord?: proposal to the Ibero-American Science \& Technology Education Consortium, ISTEC Board of Directors Meeting, Tampa, FL. December 1, 2004. 4 p. Disponível em: < https:// repository.unm.edu/handle/1928/489 > . Acesso em: 2004a.

2. in various e-newsletters. Disponível em:

- SPARC E-News, June-July 2004;

- Open Access News (News from the open access movement). Friday, June 18, $2004<$ https://mx2.arl.org/Lists/SPARC-OAForum/Message/ 793.htm > ;

- Portuguese version: "Brasil apóia acesso livre a informação cientifica" $<\underline{\text { http: } / / \text { dll.istec.org } / \text { modules.php?name }=\text { Content } \& \text { pa }=\text { showpage } \&}$ pid $=56>$.

- Translated and republished by: Svenskt Resurscentrum fuer vetenskaplig kommunikation < http://www.sciecom.org/links/APublicering/BOpen Access/>.

- The statement by librarians (Portuguese version: Recomendações do II Simpósio Internacional de Bibliotecas Digitais) < $\underline{\text { http:// }}$ dll.istec.org $/$ modules.php? name $=$ Content $\&$ pa $=$ showpage $\&$ pid $=58>$. Acesso em: 2004b.

3. PASCALE, R. T. Surfing the edge of chaos. Sloan Management Review, v. 40, n. 3, p. 83-94, 1999.

4. GELL-MANN, M. The Quark and the Jaguar. New York: Freeman, 1994.

5. KAUFFMAN, S. At home in the universe. New York: Oxford University Press, 1995.

6. HOLLAND, J. H. Hidden order. Reading, Massachusetts: AddisonWesley, 1995.

7. THE EFFECT of open access and downloads ('hits') on citation impact: a bibliography of studies. Disponível em: < $\underline{\text { htp}}$ :// opcit.eprints.org/oacitation-biblio.html>. Acesso em: 2006.

8. EYSENBACH, Gunther. Citation advantage of open access articles. PlosBiology, v. 4, n. 5, May 2006. Disponível em: < http:// biology.plosjournals.org/perlserv/?request=get-document \&doi= 10.1371/journal.pbio.0040157>. Acesso em: 2006.

9. KAO, J. Jamming: the art and discipline of business creativity. New York: HarperCollins, 1997.

10. WILSON, J.; HAYWARD, E. Winning through chaos-part 2. Credit Control, v. 20, n. 9/10, p. 35-39, 1999.

11. LEVY, Steven; STONE, Brad. The new wisdom of the web. Newsweek, p. 47- 50, Apr. 3, 2006.

12. VAN REENEN, J. Virtual work and leadership: the role of the Internet, complexity, creativity, and knowledge workers. In: BAEZAYATES, Ricardo (Ed.). The role of humanity in the information age: an ibero-american perspective. Santiago, Chile: Universidad de Chile, 2002. Disponível em: < http://www.dcc.uchile.cl/ rbaeza/libro/>. Acesso em: 30 jan. 2002.

13. MALONE, T. W.; LAUBACHER, R. J. The dawn of the e-lance economy. Harvard Business Review, n. 76, p. 144-152, 1998.

14. VAN ORSDEL, Lee C.; BORN, Kathleen. Journals in the time of Google. Library Journal, April 15, 2006. Disponível em: < http:// www.libraryjournal.com/article/CA6321722.html>. Acesso em: 2006.

15. MARUCA, R. F. Redesigning business. Harvard Business Review, n. 77, p. 19-21, 1999.

16. GOTTA, Mike; O'KELLY, Peter. Trends in social software. Report [for] EDUCAUSE Center for Applied Research (with the Burton Group). 2006. 44 p. Disponível em: < http://www.educause.edu/ LibraryDetailPage/666?ID=ERS0604 > . Acesso em: 2006. 